\title{
Treatment of complications following orofacial gangrenous infection in a resource limited setting: Experiences and a proposed classification
}

\author{
Rowland Agbara, Benjamin Fomete ${ }^{b}$, Kelvin Uchenna Omeje ${ }^{c}$, Athanasius \\ Chukwudi Obiadazie ${ }^{b}$, Sunday Olusegun Ajike ${ }^{b}$
}

\author{
Original $\quad{ }^{a}$ Oral and Maxillofacial Surgery Unit, Dental and Maxillofacial Surgery Department, \\ Article Jos University Teaching Hospital, Nigeria (Fomerly, Oral and Maxillofacial Surgery \\ Department, Ahmadu Bello University Teaching Hospital, Shika-Zaria, Nigeria)
}

${ }^{b}$ Oral and Maxillofacial Surgery Department, Ahmadu Bello University Teaching Hospital, Shika-Zaria, Nigeria.

${ }^{c}$ Oral and Maxillofacial Surgery Unit, Dental and Maxillofacial Surgery Department, Aminu Kano Teaching Hospital, Kano, Nigeria.

\begin{abstract}
Background: Orofacial gangrenous infection may result in a devastating acquired facial tissue defect which is often challenging to manage.

Objective: We present our experience in the management of noma defects in a resource limited setting.

Patients and Methods: All cases of noma that were surgically managed for secondary deformities at the oral and maxillofacial surgery unit of our hospital between 1991 and 2006 were retrospectively studied. Information retrieved included age, sex, site of orofacial gangrene, nature of orofacial defects, treatment given, duration of hospital stay and complications. Data retrieved was analyzed using Statistical Package for Social Sciences (SPSS) version 16 (SPSS Inc., Chicago, IL, USA).

Results: A total of 21 patients were treated within the period reviewed and this consisted of 18 males and 3 females. Most patients $(n=19,90.5 \%)$ presented with defect involving both facial and oral tissues. The forehead and platysma flaps were the most commonly used flaps for soft tissue defect reconstruction. The duration of hospital stay ranged from 8 days to 120 days with a mean of $42.6 \pm 27.7$ days. One patient had reankylosis one year postoperatively.

Conclusion: Orofacial gangrenous infection remains a threat to economically less developed countries such as in subSahara Africa. Its management is further complicated by the existing poor human and non human health resources in these environments. Emphasis should be on prevention, and an improvement in the current level of health resources to effectively manage these cases.
\end{abstract}

Key Words: Ankylosis, health resource, infection, poverty, surgical flaps

Received: 23 March 2018, Accepted: 22 June 2018

Corresponding Author: Agbara Rowland, University of Jos/Jos University Teaching Hospital, Jos, Plateau State, Nigeria, Tel.: +2348034627811, E-mail: row_prof@yahoo.com

ISSN: 2090-0740, June 2018, Vol.19, No.2

\section{INTRODUCTION}

Noma (commonly referred to as cancrum oris) is a clinical condition that results in varying degree of soft and hard tissues destruction in the orofacial region as a result of complex interaction of host and microbial factors leading to a wide range of functional, aesthetic and psychological complications. Although at present it is rarely encountered in clinical settings in developed countries, it remains an ever present health challenge in economically underdeveloped countries such as in the sub-Sahara Africa ${ }^{1}$.The condition is usually preceded by an acute necrotizing ulcerative gingivitis (Vincent's disease) which progresses from a gingival lesion to a destructive and devastating orofacial tissue disease. The most important predisposing factor has been identified as poverty ${ }^{2}$. Other related factors include poor oral hygiene, chronic malnutrition, poor environmental sanitation and infection with bacterial and viral agents such as in malaria, measles, chicken pox and human immunodeficiency virus (HIV) ${ }^{1}$. However, in some cases of noma, no predisposing factor(s) has been identified $^{3}$. Children are more commonly affected although adult cases have been noted especially in patients with HIV and malignancies ${ }^{3-6}$. There appear to be no significant sex predilection, however, some studies have reported a higher female predisposition ${ }^{5,7}$. Microbiological studies of the disease have implicated the group of organisms referred to as the fusospirochetal complex as the main culprit. 8 The clinical features in acute presentation includes fever, tachycardia, anorexia, oral ulcerations, halitosis, cervical lymphadenopathy, blue-black discoloration of the skin over the involved area and intra/extra oral pus discharge?. 
Treatment of orofacial gangrenous infection consists of four parts; Chemotherapy, local wound management, general management and surgical treatment of secondary deformities ${ }^{10}$.

The purpose of this study is to highlight our experience in the surgical treatment of 21 patients with post noma defect in a resource limited setting.

\section{METHODOLOGY:}

All cases of orofacial gangrene that were surgically managed for secondary deformities at the oral and maxillofacial surgery unit of a regional teaching hospital between 1991 and 2006 were retrospectively studied. Cases that had only initial treatment for the active stage of the disease without surgical treatment of secondary deformities were excluded. Information was sourced from patient's case notes and operating theatre register. Information retrieved included age, sex, site of orofacial gangrene, nature of orofacial defects, treatment given, duration of hospital stay and complications. Data retrieved was analyzed using Statistical Package for Social Sciences (SPSS) version 16 (SPSS Inc., Chicago, IL, USA) and Microsoft Office Excel 2007 (Microsoft, Redmond, WA, USA). Findings from descriptive statistics were represented in the form of tables.

\section{Initial treatment:}

Following presentation during the active phase of the disease, initial treatment consisted of administration of antibiotics (essentially penicillin and metronidazole in our environment) and antipyretics, intravenous fluid replacement, oral care, nutritional support, and blood transfusion where indicated. Wound debridement was undertaken only if there is a clear demarcation between the gangrenous area and normal tissue to avoid unnecessary removal of healthy tissue. Nutritional support consisted of locally prepared high calorie diet commonly referred to as kwash pap whose composition include millet, ground nuts, soybeans and crayfish. However, patients in the active phase of the disease whose parents refused admission were managed on outpatient basis using antibiotics in addition to oral hygiene and nutritional advice.

\section{Definitive treatment:}

Following progression to the stable phase of the disease and restoration of clinical and laboratory indices such as weight, temperature, respiratory rate, breath sounds, hemoglobin level and urea/electrolyte, hard and soft tissue complications of the disease were treated. This was commonly achieved using general anesthesia.

\section{Classification:}

We classified noma based on type of tissue involvement as seen in clinical practice into types A, and B. region.

Type A noma: Only limited to soft tissue of the orofacial

Type B noma: Involves both soft tissues and bones of the orofacial region.

The above types are further subclassified based on pattern of tissue involvement into:

Types A1 or B1: Involves only intraoral tissues, extraoral tissues unaffected (Cancrum oris)

Types A2 or B2: Involves only extraoral tissues, intraoral tissues unaffected (Cancrum facialis).

Types A3 or B3: Involves both extraoral and intraoral tissues (Cancrum orofacialis).

\section{RESULTS}

A total of 21 patients were treated in the stable phase for hard and soft tissue complications following orofacial gangrenous infection within the period reviewed, and this consisted of 18 males and 3 females, giving a male to female ratio of $6: 1$. The ages of the patients ranged from 4 years to 26 years with a mean of $16.10 \pm 6.20$ years. Majority $(n=11,52.4 \%)$ of the patients were in the 2 nd decade of life.

The presenting complain were facial soft tissue defect $(n=12,57.1 \%)$, inability to open mouth $(n=5,23.8 \%)$, and a combination of facial soft tissue defect/inability to open mouth $(\mathrm{n}=4,19.0 \%)$. The duration of presenting complain was documented only in 17 patients and this ranged from 0.04 years to 19.00 years with a mean of 9.80 years. The site of soft tissue defect in 16 patients is shown in table 1 and the cheek accounted for the highest number $(n=5)$ of defects. Of the 21 cases studied, type A3 noma defect accounted for $10(47.6 \%)$ cases, type B3 noma accounted for defect in $9(42.9 \%)$ patients, while the remaining 2 $(9.5 \%)$ patients were of type A2 presentation.

The anesthetic method used for all the patients was general anesthesia (GA). The method of administration of GA was only documented in $5(23.8 \%)$ patients' and this was all via elective tracheotomy. Treatment for hard tissue complication (ankylosis) consisted of body ostectomy $(\mathrm{n}=8,88.9 \%)$ patients and angle ostectomy $(\mathrm{n}=1$, $11.1 \%)$. Soft tissue complications were managed using locoregional flaps (Table 2). The forehead and platysma flaps were the most commonly used flaps for soft tissue defect reconstruction. The duration of hospital stay ranged from 8 days to 120 days with a mean of $42.6 \pm 27.7$ days.

Complications noted postoperatively included infection of flap recipient bed in $3(14.3 \%)$ patients, and reankylosis in $1(4.8 \%)$ patient one year postoperatively. 
Table 1: Sites of reconstructed soft tissue defect following orofacial gangrene

\begin{tabular}{|l|c|c|}
\hline Sites & Frequency & Percent \\
\hline upper lip & 3 & 18.8 \\
\hline upper and nose & 2 & 12.5 \\
\hline cheek & 5 & 31.2 \\
\hline nose & 1 & 6.2 \\
\hline infraorbital region & 1 & 6.2 \\
\hline lower lip and chin & 2 & 12.5 \\
\hline $\begin{array}{l}\text { cheek and upper/ } \\
\text { lower lip }\end{array}$ & 1 & 6.2 \\
\hline medial canthus & 1 & 6.2 \\
\hline Total & 16 & 100.0 \\
\hline
\end{tabular}

Table 2: Types of locoregional flaps used in soft tissue defect reconstruction

\begin{tabular}{|l|c|c|}
\hline Flap & Frequency & Percent \\
\hline forehead flap & 4 & 28.6 \\
\hline $\begin{array}{l}\text { random based arm } \\
\text { flap }\end{array}$ & 1 & 7.1 \\
\hline nasolabial flap & 1 & 7.1 \\
\hline bernard flap & 1 & 7.1 \\
\hline $\begin{array}{l}\text { forehead and } \\
\text { temporalis flap }\end{array}$ & 2 & 14.3 \\
\hline platysma flap & 3 & 21.4 \\
\hline Estlander flap & 1 & 7.1 \\
\hline $\begin{array}{l}\text { random forearm } \\
\text { flap }\end{array}$ & 1 & 7.1 \\
\hline \begin{tabular}{l} 
Total \\
\hline
\end{tabular} & 14 & 100.0 \\
\hline
\end{tabular}

Table 3: Proposed classification of orofacial gangrenous infection

\begin{tabular}{|l|l|}
\hline Type & Characteristic feature \\
\hline Type I OGI & $\begin{array}{l}\text { Defect is solely intraoral without skin } \\
\text { involvement (Cancrum oris). }\end{array}$ \\
\hline Type II OGI & $\begin{array}{l}\text { Defect is located extraorally with no intraoral } \\
\text { involvement (Cancrum facialis). }\end{array}$ \\
\hline Type III OGI & $\begin{array}{l}\text { Defect involve both extraoral and intraoral } \\
\text { structures (Cancrum orofacialis). }\end{array}$ \\
\hline
\end{tabular}

Note: OGI $=$ Orofacial gangrenous infection (Each type is further sub-classified into A and B depending on nature of tissue involved)

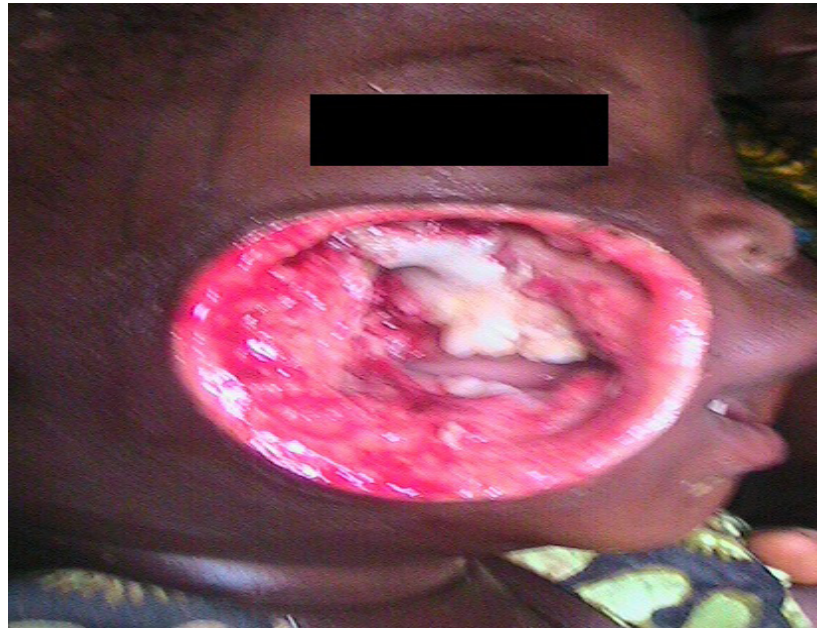

Fig. 1: Presentation of type A3 noma showing stable phase of disease. Exposed bone not involved.
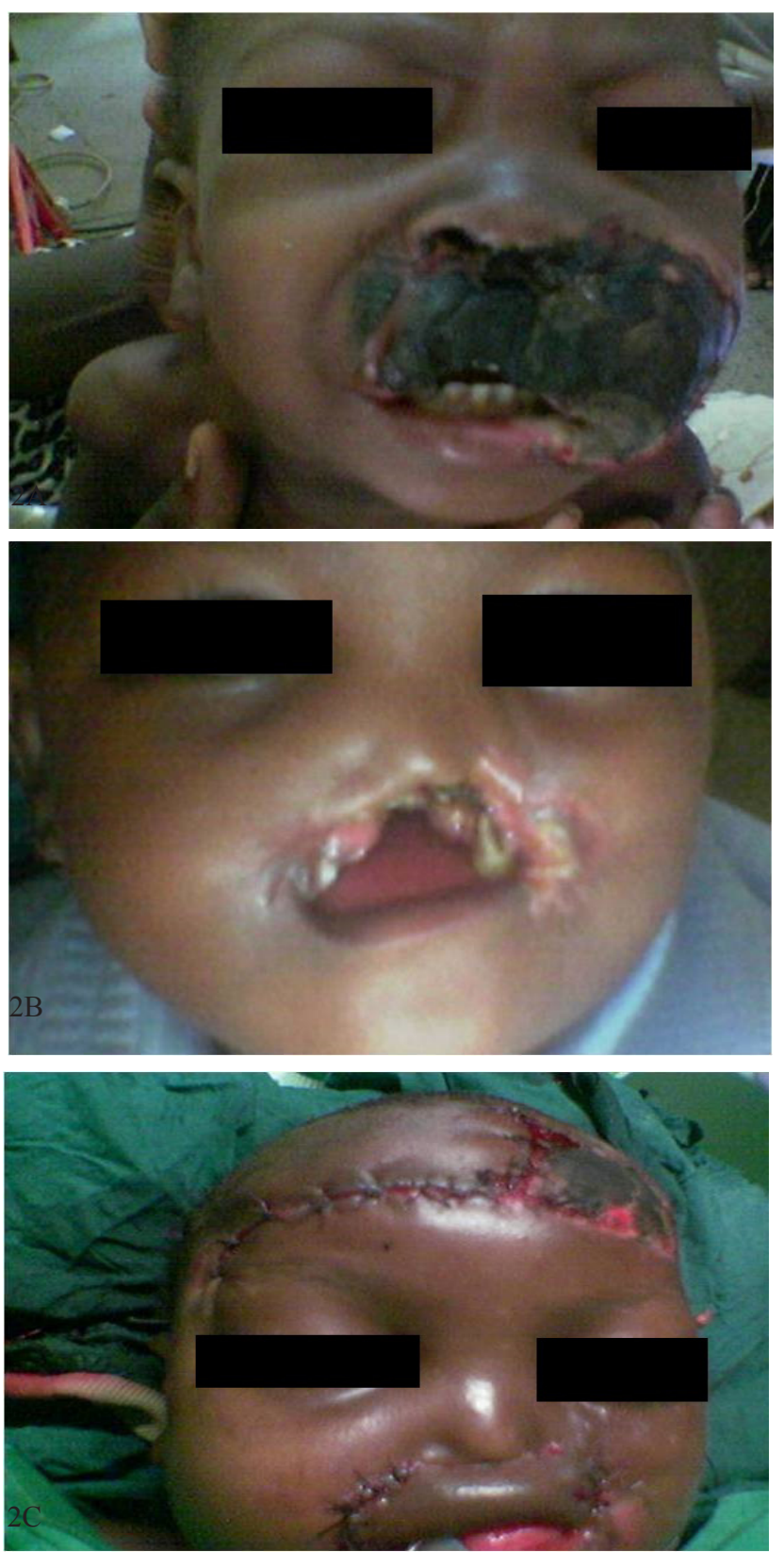

Fig. 2: Presentation of type B3 noma: (a) Acute presentation (b) stable phase (c) first stage repair with forehead flap. 


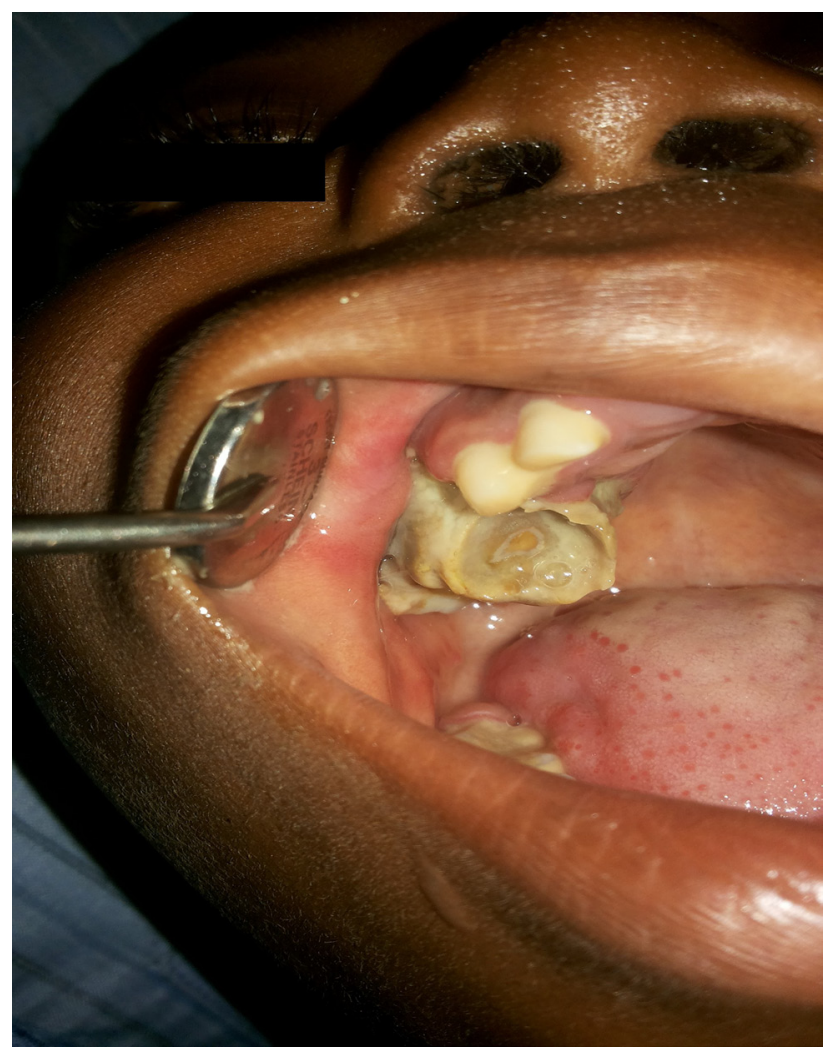

Fig. 3: Presentation of type B1 noma.

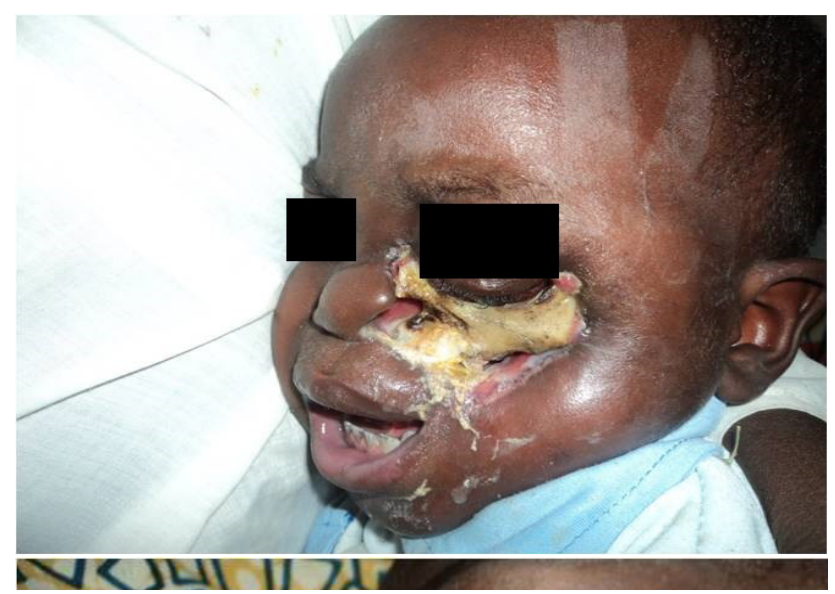

Fig. 4: Presentation of type B2 noma.

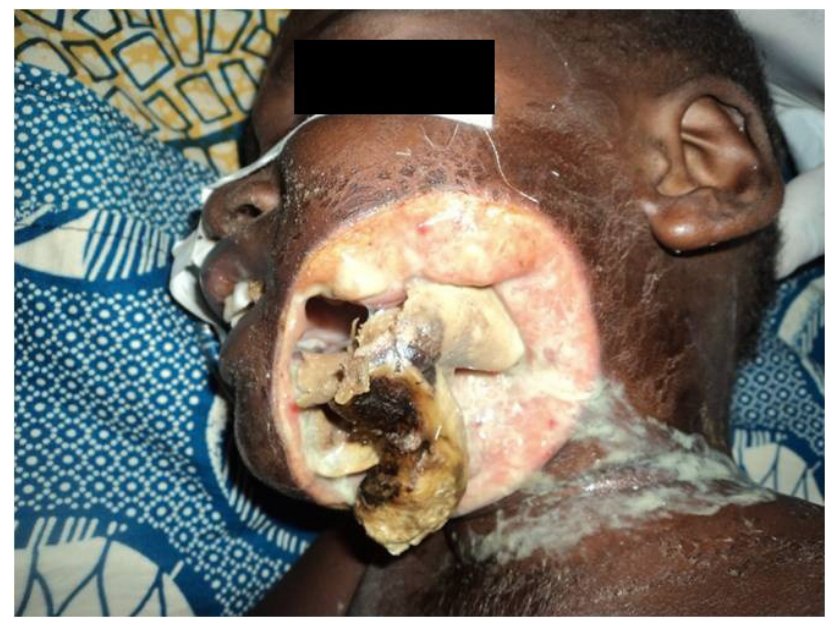

Fig. 5: Cheek involvement with bone necrosis.

\section{DISCUSSION}

Noma remains a threat in economically less developed countries such as in sub-Sahara Africa. This threat is ever present due to the persistence of gross poverty, poor access to health and other factors implicated in orofacial gangrenous infection. ${ }^{[8,11]}$. Following resolution of the active stage of the disease, the victims are often left with disfiguring facial defects requiring reconstruction to improve their functional, aesthetic and psychological status.

In this study, more males than females were managed for secondary deformities. This is in agreement with previous findings ${ }^{[13]}$. However; some previous studies ${ }^{[7,13]}$ reported a female preponderance. It is likely that functional derangement rather than aesthetic problem was the main motivation for these males to seek treatment many years after the active stage of the disease. Males are generally less concerned with aesthetics in our environment.

Majority of the cases $(64.5 \%)$ were noted in patients below 5 years of age, similar to previous findings ${ }^{[7,14]}$ However, orofacial gangrene have also been reported in preterm/term neonates ${ }^{[15,16]}$ and in adults ${ }^{[5,6]}$. The interval between the active phase of the disease and presentation for secondary deformities by the patients in this study ranged from 2 weeks to 19 years with a mean of $9.8 \pm 6.7$ years. The reasons for the long wait before seeking treatment for secondary deformities was not documented but it is likely related to their inability to afford the cost of surgery, cultural/religious influence, and lack of awareness of possible surgical correction.

Traditionally, the term "cancrum oris" refers to a severe gangrene of the soft and hard tissues of the mouth, face, and neighboring areas ${ }^{[2]}$. However, the word "oris" in its strict use means mouth. In clinical practice, noma may involve the face may without involving the oral cavity just as it may involve the mouth without facial involvement. In view of this, we propose that the term noma instead of cancrum oris be used and that this be classified based on the type of tissue involvement into types A (only tissues involved) and B (tissues and bone involved). Each of these type can be further subclassified based on pattern of tissue involvement (Table 3) into A1 or B1 (Involves only intraoral tissues, extraoral tissues unaffected); A2 or B2 (Involves only extraorally tissues, intraoral tissues unaffected); and A3 or B3 (This involves both extraoral and intraoral tissues). Based on this classification, type A3 and B3 noma defect accounted for the highest number of patients. The higher number of type A3 (Fig. 1) and B3 (Fig. 2) noma noted in this study is consistent with findings from previous studies ${ }^{[7,14]}$. There were no cases of A1, A2, B1 (Fig. 3), and B2 (Fig. 4) noma defects managed. Generally the subclasses A2, A3, B2 and B3 are more challenging to manage.

The lip ( $\mathrm{n}=8,50.0 \%)$ accounted for the highest number 
noma associated soft tissue defect followed by the cheek $(\mathrm{n}=5,31.3 \%)$ (Fig.5). Similar pattern of facial soft tissue involvement was previously reported ${ }^{[7]}$. However, a previous study reported the cheek as the most frequent site of noma associated soft tissue defect ${ }^{[17]}$. The upper lip $(n=5)$ was slightly more affected than the lower lip $(n=3)$, similar to previous report ${ }^{[17]}$.

Administration of general anesthesia remains a challenge in patients with post noma defect as a result of limited mouth opening. Where conventional orotracheal or nasotracheal intubation is not feasible, methods advocated include facemask ventilation, transtracheal jet ventilation, blind nasal intubation, fibreoptic intubation and tracheostomy ${ }^{[18,19]}$. However, the choice of technique should be individualized (based on parameters such as interincisal distance and ability to subluxate the mandible) rather than generalized $^{[19]}$. Tracheostomy was used for administration of inhalational anesthesia in 5 of the 9 patients. Although fibreoptic laryngoscope is presently available in our centre, only few anesthetists are conversant and skillful with its use. Hence, the maxillofacial surgeon in our environment should be ever ready to perform a tracheotomy due to increased repeated failed fibreoptic intubation or blind nasal intubation in these cases.

All the soft tissue defects were reconstructed using pedicled flaps and the forehead $(\mathrm{n}=6,42.9 \%)$ and platysma $(n=3,21.4 \%)$ flaps were the commonly used flaps. This finding is similar to previous studies ${ }^{[7,20]}$. In this present study, free flaps were not used in soft tissue reconstruction and this is mainly due the non availability of skilled personnel in our environment. Free flaps have been advocated for reconstruction of centrofacial noma defects due to the disappointing outcomes with locoregional flap ${ }^{[21]}$ However, in our experience, locoregional flaps can still provide acceptable results in noma defects reconstruction including some cases of centrofacial defects, especially where microvascular surgery is not feasible. This has been highlighted in previous studies ${ }^{[5,18]}$.

Limited mouth opening in patients studied was mainly due to extra-articular ankylosis in the form of maxilla-mandibular fusion. This was managed using mandibular ostectomy procedures and this consisted of body $(n=8,88.9 \%)$ and angle $(n=1,11.1 \%)$ ostectomies. The management of limited mouth opening post noma depends on the type of tissues involved, extent of the tissues involved, surgeon's skill and facilities available among other factors. Limited mouth opening from scar tissue formation may be managed by scar tissue excision (with or without skin graft) or by scar tissue distraction using jaw exerciser or distraction devices ${ }^{[22]}$ with varying success rates. In maxillo-mandibular fusion, the release of ankylosis involves the removal of the bony bar between the mandible and maxilla, or a neoarthrosis via a mandibular ostectomy procedure (which may be body or ramus ostectomy) with or without soft tissue interposition ${ }^{[23,24]}$
The duration of hospital stay ranged from 8 days to 120 days with a mean of $42.63 \pm 27.89$. The long duration of hospital stay recorded in this study may be related to the fact that most of the patients came from far distances and been poor, could not afford to be transporting themselves repeatedly to the hospital for their staged treatment. Similarly, the non availability of skilled personnel in peripheral health centers to monitor the progress of these patients post surgery may be contributory.

Four patients had post surgical complication and this consisted of wound infection with partial breakdown of flap in three patients, and reankylosis in a 13 year old patient one year post surgery. Non compliance with mouth exercises remains the most important factor for reankylosis in our environment. The presence of pain during mouth exercise especially in the immediate period and few weeks post surgery results in non compliance particularly in children. This requires dedication on the part of the parents and guardians to maintain the achieved mouth opening.

Poor response to follow up remains a challenge in our environment. This has greatly affected our ability to make objective assessment of treatment outcome over a long period of time. Cost of transportation, feeling of wellbeing following surgery, and ignorance may be possible causes of poor compliance to follow up review appointments. This difficulty in assessing treatment outcome is further worsened by the fact that telecommunication facilities were non-existent in our country within this period reviewed.

\section{CONCLUSION}

Although the incidence of noma has largely reduced, it remains an ever present threat in our environment since some of the important predisposing factors are still prevalent especially in the face of global economic recession, insurgencies and famine. Secondary deformities from noma are quite challenging to manage; therefore there should be continual emphasis on prevention through public health awareness, and an efficient national health insurance scheme to ensure universal health coverage.

\section{CONFLICT OF INTEREST}

There are no conflicts of interest.

\section{REFERENCES}

1. Ogbureke KUE, Ogbureke EI. NOMA: A Preventable "Scourge" of African Children. The Open Dentistry Journal 2010; 4: 201-6.

2. Enwonwu CO. Noma: a neglected scourge of children in sub-Saharan Africa. WHO Bull. 1995; 73: 541-5.

3. Stassen LFA, Batchelor AGG, Rennie JS, Moos KF. Cancrum oris in an adult caucasian female. Br J Oral Maxillofac Surg. 1989; 27: 417-422. 
4. Koech KJ. Cancrum oris in an adult with human immunodeficiency virus infection: case report. East Afr Med J. 2010; 87(1): 38-40.

5. Chidzonga MM, Mahomva L. Noma (cancrum oris) in human immunodeficiency virus infection and acquired immunodeficiency syndrome (HIV and AIDS): clinical experience in Zimbabwe. J Oral Maxillofac Surg. 2008; 66(3): 475-85.

6. Krishnamurthy A, Vaidhyanathan A, Srinivas S, Sundersingh S, Krishnarathinam. Cancrum Orisassociated with Acute Myeloid Leukemia: A Forgotten Disease. Int J Head Neck Surg. 2010;1(3):167-9.

7. Lazarus D, Hudson DA. Cancrum oris - a 35-year retrospective study. S Afr Med J. 1997; 87: 1379-1382.

8. Enwonwu CO, Falkler WA, Idigbe EO. Oro-facial gangrene (noma/cancrum oris): pathogenetic mechanisms. Crit Rev Oral Biol Med. 2000; 11(2):159-71.

9. Enwonwu $\mathrm{CO}$, Falkler WA, Phillips RS. Noma (cancrum oris). Lancet 2006; 368: 147-156

10. Adeola DS, Eguma SA, Ononiwu CN. Cancrum oris among Nigerian children. Niger J Surg Res. 2004; 6: 7-10.

11. Ufuoma EJ. Donor Support for Community Health Financing: Options and Opportunities for Sub-Saharan African Communities. American Journal of Public Health Research, 2013; 1 (6): 129-134.

12. Ouoba K, Sanou I, Dao M, Kam L, Ouédraogo A, Ouédraogo R, Sawadogo A. Progressive noma: 27 cases seen at Ouagadougou Central Hospital. Dakar Medical 1998; 43(1): 45-8.

13. Nath S, Jovic G. Cancrum oris: management, incidence, and implications of human immunodeficiency virus in Zambia. Plast Reconstr Surg. 1998; 102(2): 350-7.

14. Oginni FO, Oginni AO, Ugboko VI, Otuyemi OD. A survey of cases of cancrum oris seen in Ile-Ife, Nigeria. Int J Paed Dent. 1999; 9:75-80.
15. Juster-Reicher A, Mogilner BM, Levi G, Flidel O, Amitai M. Neonatal noma. Am J Perinatol. 1993; 10(6): 409-11.

16. Nayak PA,Nayak UA,Khandelwal V,Gupta A. Noma neonatorum. BMJ Case Rep. 2013. doi:10.1136/bcr2013-009912.

17. Bourgeois DM, Diallo B, Freih C, Leclercq MH. Epidemiology of the incidence of oro-facial noma: A study of cases in Dakar, Senegal, 1981-1993. Am. J. Trop. Med. Hyg. 1999; 61(6): 909-913.

18. Adekeye EO, Lavery KM, Nasser NA. The versatility of pectoralis major and latissimus dorsi myocutaneous flaps in the reconstruction of cancrum oris defects of children and adolescents. J Maxillofac Surg. 1986; 14(2): 99-102.

19. Coupe MH, Johnson D, Seigne P, Hamlin B. Airway Management in Reconstructive Surgery for Noma (Cancrum Oris). Anesth Analg. 2013;117:210-7.

20. Devi S R, Gogoi M. Aesthetic restoration of facial defect caused by cancrum oris: A case report. Indian J Plast Surg. 2003; 36: 131-3

21. Giessler GA, Cornelius CP, Suominen S, Borsche A, Fieger AJ, Schmidt AB, Fischer H. Primary and secondary procedures in functional and aesthetic reconstruction of noma-associated complex central facial defects. Plast Reconstr Surg. 2007; 120(1): 134-43.

22. Holle J. Lockjaw treatment after noma in the third world. J Craniofac Surg. 2009; 20 Suppl 2:1910-2.

23. Adekeye EO, Ord RA. Cancrum oris: principles of management and reconstructive surgery. J Maxillofac Surg. 1983; 11(4): 160-70.

24. Adams-Ray WE, James JH. Cancrum Oris: functional and cosmetic reconstruction in patients with ankylosis of the jaws. Br J Plast Surg 1992; 45: 193-8. 